\title{
POTENTIODYNAMIC CHARACTERISTICS OF RUTHENIZED PLATINUM ELECTRODES IN SULPHURIC ACID SOLUTIONS
}

\author{
R.O. LEZNA \\ Departamento de Química, Universidad Nacional de Mar del Plata, Funes 3250, (7600) Mar del Plata \\ (Argentina)
}

N.R. DE TACCONI and A.J. ARVİA

Instituto de Investigactones Fisicoquímicas Teóricas y Apltcadas, INIFTA. Casilla de Correo 16, Sucursal 4, 1900 La Plata (Argentina)

(Received 10th September 1982; in revised form 29th November 1982)

\begin{abstract}

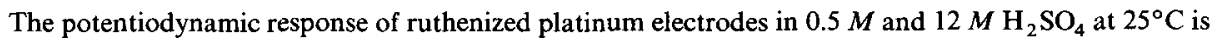
investigated. The $E / I$ profiles depend on the electrode history and involve sintering-type effects. In $12 M$ $\mathrm{H}_{2} \mathrm{SO}_{4}$ they can be analysed in more detail because the separation of the H-adatom and O-electroadsorption potential ranges is greater than in $0.5 \mathrm{M} \mathrm{H}_{2} \mathrm{SO}_{4}$. Thus, four different stages related to the oxide layer are distinguished. The interpretation of the corresponding overall processes is given in terms of the equilibrium potentials of the $\mathrm{Ru} / \mathrm{H}_{2} \mathrm{O}$ system and the reversibility characteristics of the different stages derived from the various potential/time perturbation programs are discussed through reaction patterns previously considered for these reactions on other noble metals.
\end{abstract}

\section{INTRODUCTION}

The electrocatalytic properties of ruthenium are well recognized through its applications in different technical electrochemical processes [1-5]. The electrochemical characteristics of ruthenium in acid electrolytes are more complex than those of the platinum group metals [6-11]. Thus, the processes in the $\mathrm{H}$-region include $\mathrm{H}$ deposition and sorption into $\mathrm{Ru}, \mathrm{H}$-adsorption onto its surface and $\mathrm{H}$ diffusion into $\mathrm{Ru}$ [12]. The processes in the O-region are remarkably dependent on the potential perturbation conditions. Thus, a fresh $R \mathbf{u}$ electrode which is potential cycled between $0.05 \mathrm{~V}$ and ca. $1.2 \mathrm{~V}$ (RHE) exhibits a current/potential profile that corresponds to irreversible O-monolayer formation and reduction. After about $20-30$ cycles, the $I / E$ profile in this case is changed with a redistribution of the O-monolayer formation and reduction charge with respect to potential, although the modification of the real electrode area remains unchanged to within 5\%. On the other hand, when the potential cycling covers from ca. $0.05 \mathrm{~V}$ to $1.4 \mathrm{~V}$ (RHE) a thickened oxide film is produced. The latter shows a remarkably reversible 
potentiodynamic profile that is due to solid-state redox reactions in the film [13,14]. This active-type ruthenium oxide electrode, and thermally formed $\mathrm{RuO}_{2}$ electrodes, are of interest as electrocatalytic modes in technical processes although $\mathrm{RuO}_{2}$ formed at $>1.0 \mathrm{~V}$ appears less stable electrochemically than $\mathrm{RuO}_{2}$ formed thermally [15]. On the other hand, the dissolution rate of ruthenium in sulphuric acid electrolytes during cycling to $1.54 \mathrm{~V}$ is much greater than that previously reported for other noble metals [10].

This paper reports the potentiodynamic behaviour of different oxygen-containing films electrochemically formed on ruthenium, particularly in sulphuric acid solutions of relatively high concentrations, and attempts to correlate potential regions of the reversible cyclic voltammetry profiles to thermodynamic predictions of the $\mathrm{Ru} / \mathrm{H}_{2} \mathrm{O}$ interface.

\section{EXPERIMENTAL}

Ruthenium working electrodes were prepared by electroplating the metal on a 1 $\mathrm{mm}$ diameter platinum wire $\left(0.25 \mathrm{~cm}^{2}\right.$ apparent area) using a $1 M \mathrm{NH}_{4} \mathrm{Cl}$ containing $1 \% \mathrm{RuCl}_{3} \cdot 3 \mathrm{H}_{2} \mathrm{O}$, for $15 \mathrm{~min}$. at $25^{\circ} \mathrm{C}$, the initial current at $-0.4 \mathrm{~V}$ (vs. SCE) being

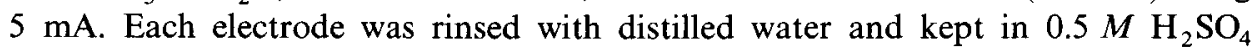
before use. The potential of the working electrode was measured against a reversible hydrogen electrode, and the latter was connected through a Luggin-Haber capillary tip. The counterelectrode was made either of a large area platinum sheet or of a glassy carbon rod. The three-electrode arrangement was mounted in a conventional

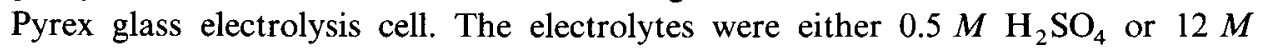
$\mathrm{H}_{2} \mathrm{SO}_{4}$, which were prepared from $98 \% \mathrm{AR}$ sulphuric acid in triply distilled water. The working electrode was perturbed with various potential/time programs involving either simple or combined perturbation functions and covering a suitable range of the different perturbation parameters. Runs were made at $25^{\circ} \mathrm{C}$ under a purified nitrogen atmosphere.

The problem of defining real areas of electrodes in the case of $\mathrm{Ru}$ through the $\mathrm{H}$ adatom electro-oxidation/electroreduction charges has been considered previously by various authors, as well as the time dependence of the electrode areas upon anodic/cathodic cycling [7,10,20]. Therefore, in order to rationalize the data for possible comparison with other reported results, current densities and charge densities are given per geometric $\mathrm{cm}^{2}$ of substrate electrode.

\section{RESULTS}

The potentiodynamic response of freshly electrodeposited $\mathrm{Ru}$ changes, during the repetitive triangular potential cycling (RTPC), from a display which implies large anodic $\left(Q_{\mathrm{a}}\right)$ and cathodic $\left(Q_{\mathrm{c}}\right)$ charges associated with net irreversible processes, to a decrease of both $Q_{\mathrm{a}}$ and $Q_{\mathrm{c}}$, the corresponding reactions approaching a better definition of the different surface processes [13]. It appears as if the electrodeposited metal re-accomodates in a way which suggests a probable electrochemical sintering 


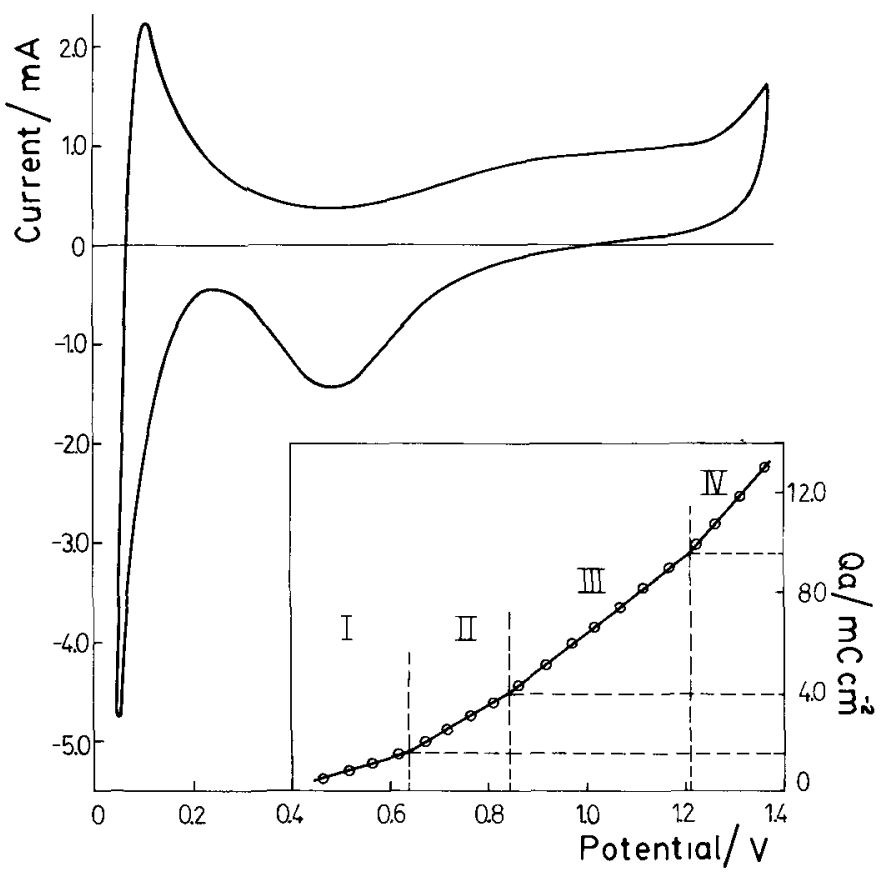

Fig. 1. Potentiodynamic $I / E$ profile. Ruthenized $\mathrm{Pt}, 0.25 \mathrm{~cm}^{2}$ apparent area; $0.1 \mathrm{~V} / \mathrm{s} ; 12 \mathrm{M} \mathrm{H}_{2} \mathrm{SO}_{4}$; $25^{\circ} \mathrm{C}$. The anodic charge vs. potential obtained by integrating the potentiodynamic $I / E$ profile is included in the figure.

$[16,17]$. Once the stabilized situation is achieved, no change in the shape of the voltammogram is observed at any amplitude of the RTPC, although a small decrease in charge continues for a longer time. These results suggest that electrodeposited $\mathrm{Ru}$ electrodes are able to attain either a remarkable, inactive or a net active electrochemical behaviour, depending on their history. These characteristics are also observed to some extent for Pd and Rh electrodes in acid electrolytes $[18,19]$.

The following results are obtained on $\mathrm{Ru}$ electrodes which exhibit the characteristics of active electrodes in the potential range of the oxygen-containing layer formation. This does not preclude that a residual sintering effect is still present, but this effect can be disregarded by properly defining the reference charge for comparison.

The best resolution of the potentiodynamic $E / I$ displays was obtained in $12 \mathrm{M}$ $\mathrm{H}_{2} \mathrm{SO}_{4}$ solution. The conventional stabilized $E / I$ display resulting after a RTPC between $E_{\mathrm{s}, \mathrm{c}}=0.05 \mathrm{~V}$ and $E_{\mathrm{s} . \mathrm{a}}=1.4 \mathrm{~V}$, at $0.1 \mathrm{~V} / \mathrm{s} \mathrm{(Fig.} \mathrm{1)} \mathrm{shows,} \mathrm{at} \mathrm{potentials} \mathrm{lower}$ than $0.3 \mathrm{~V}$, clear current contributions related to the electroformation and electrodissolution of hydrogen and, in the $0.9 \mathrm{~V}$ to $1.4 \mathrm{~V}$ range, a limiting current due to the formation of oxygen containing species and the corresponding electroreduction current peak at ca. $0.5 \mathrm{~V}$.

The anodic charge $\left(Q_{\mathrm{a}}\right)$ related to the electro-formation of oxygen-containing 


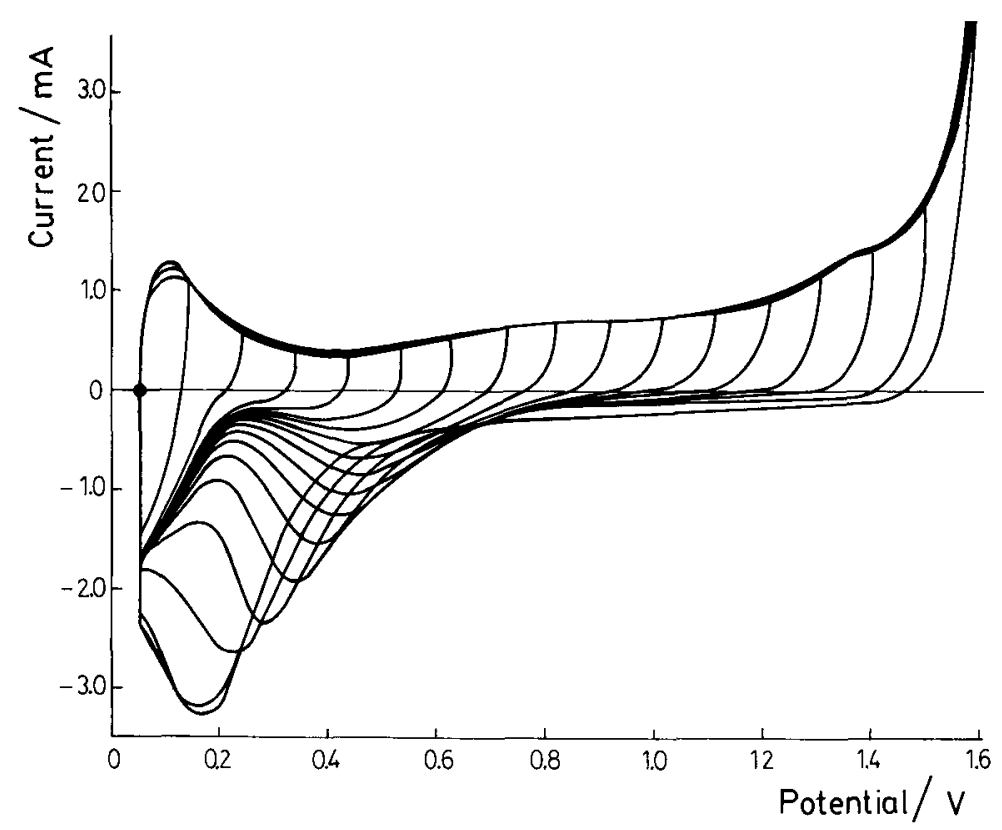

Fig. 2. Potentiodynamic $I / E$ profiles with a constant $E_{\mathrm{s}, \mathrm{c}}$ value and different $E_{\mathrm{s}, \mathrm{a}}$. Ruthenized $\mathrm{Pt}, 0.25 \mathrm{~cm}^{2}$ apparent area; $0.1 \mathrm{~V} / \mathrm{s} ; 12 \mathrm{M} \mathrm{H}_{2} \mathrm{SO}_{4} ; 25^{\circ} \mathrm{C}$.

species increases with the applied potential $\left(E_{\mathrm{s}, \mathrm{a}}\right)$. In $0.5 M \mathrm{H}_{2} \mathrm{SO}_{4}$, the $Q_{\mathrm{a}}$ vs. $E_{\mathrm{s}, \mathrm{a}}$ relationship exhibits three linear portions in good agreement with the results previously published by Conway and co-workers [6], but in $12 \mathrm{M} \mathrm{H}_{2} \mathrm{SO}_{4}$ the same type of plot shows four different linear regions, which cover the following potential ranges: $0.54-0.62 \mathrm{~V}$ (I), $0.62-0.85 \mathrm{~V}$ (II), $0.85-1.2 \mathrm{~V}$ (III) and $1.2-1.4 \mathrm{~V}$ (IV), respectively. This difference between $0.5 M \mathrm{H}_{2} \mathrm{SO}_{4}$ and $12 M \mathrm{H}_{2} \mathrm{SO}_{4}$ may be related to the greater separation between the potential range of the $\mathrm{H}$-adatoms and that corresponding to the initiation of the oxygen electroadsorption as the electrolyte concentration increases. The latter situation is well established for Pt electrodes in contact with $\mathrm{H}_{2} \mathrm{SO}_{4}$ solutions of different concentrations.

The $E / I$ profiles run from $E_{\mathrm{s}, \mathrm{c}}=0.05 \mathrm{~V}$ and $E_{\mathrm{s}, \mathrm{a}}$ gradually decreased (Fig. 2) show that the O-electro-desorption occurs at more positive potentials as $E_{\mathrm{s}, \mathrm{a}}$ is stepwise decreased. Each $E / I$ profile was run after holding the electrode at $0.05 \mathrm{~V}$ for $1 \mathrm{~min}$ to standarize the removal of oxide species formed in the previous positive scan and to start each $E / I$ trace from reproducible initial conditions. This indicates that the early stage associated with the O-electroadsorption approaches the characteristics of a reversible reaction. Potential holding times in the 1-5 min range gave the same results. On the other hand, when $E_{\mathrm{s}, \mathrm{a}}$ is kept at a constant value $\left(E_{\mathrm{s} . \mathrm{a}}=1.10 \mathrm{~V}\right)$ and $E_{\mathrm{s}, \mathrm{c}}$ is progressively decreasing (Fig. 3), both the anodic $\left(Q_{\mathrm{a}}\right)$ and the cathodic $\left(Q_{\mathrm{c}}\right)$ charges increase and a new cathodic peak appears at 


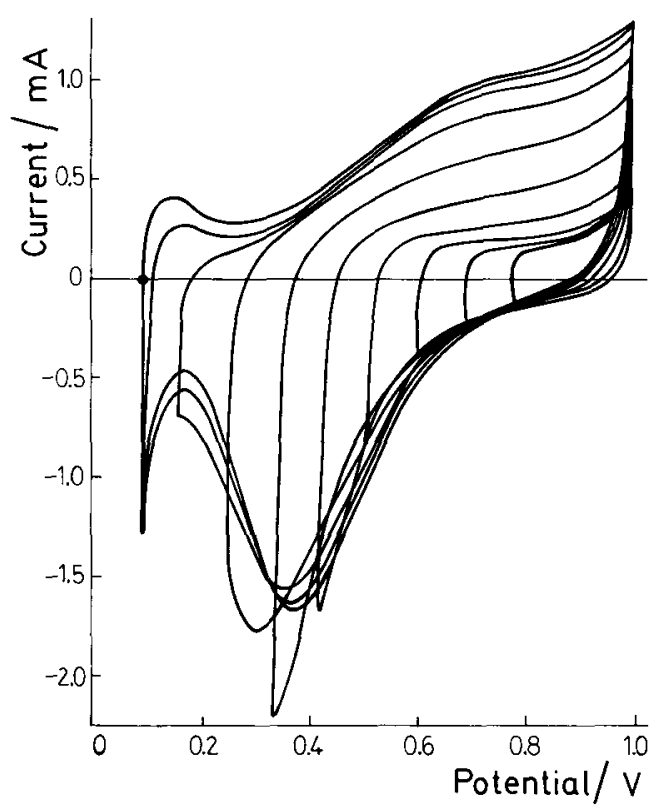

Fig. 3. Potentiodynamic $I / E$ profiles with a constant $E_{\mathrm{s}, \mathrm{a}}$ value and gradually decreasing $E_{\mathrm{s.c}}$. Ruthenized $\mathrm{Pt}, 0.25 \mathrm{~cm}^{2}$ apparent area; $0.1 \mathrm{~V} / \mathrm{s} ; 12 \mathrm{M} \mathrm{H}_{2} \mathrm{SO}_{4} ; 25^{\circ} \mathrm{C}$.

potentials lower than the peak potential $\left(E_{\mathrm{p}, \mathrm{r}}\right)$ related to the electroreduction of the oxygen-containing species in the RTPC $E / I$ displays at $0.1 \mathrm{~V} / \mathrm{s}$. Likewise, when $E_{\mathrm{s}, \mathrm{c}}$ is lower than $E_{\mathrm{p}, \mathrm{r}}$, the $E / I$ profile again approaches the conventional stabilized $E / I$ display.

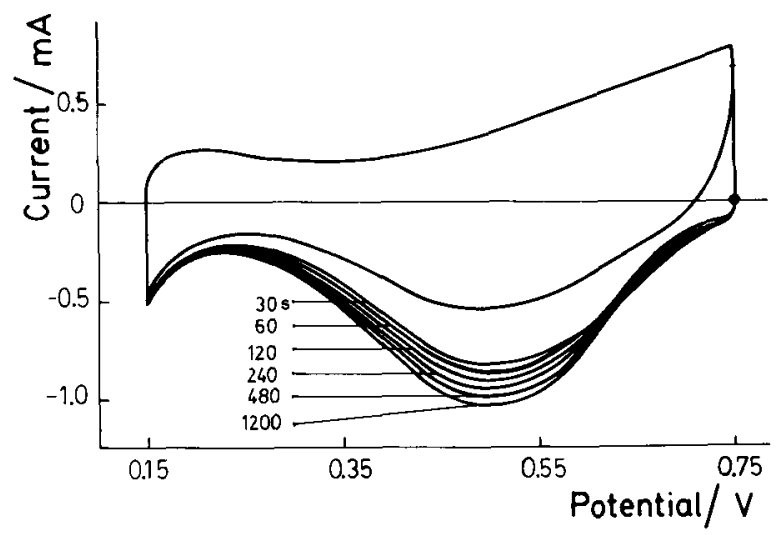

Fig. 4. Potentiodynamic $I / E$ profiles including a potential holding at $E_{\tau}=0.75 \mathrm{~V}$ during different $\tau$. Ruthenized $\mathrm{Pt}, 0.25 \mathrm{~cm}^{2}$ apparent area; $0.1 \mathrm{~V} / \mathrm{s} ; 12 \mathrm{M} \mathrm{H}_{2} \mathrm{SO}_{4} ; 25^{\circ} \mathrm{C}$. 


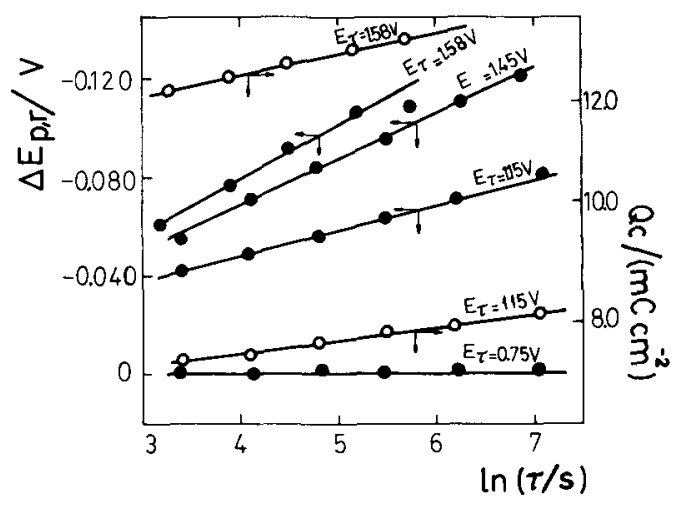

Fig. 5. (๑) Plot of $\Delta E_{\mathrm{p}, \mathrm{r}}$ vs. In $\tau$. Data corresponding to four different values of $\tau$. Ruthenized $\mathrm{Pt}, 0.25 \mathrm{~cm}^{2}$ apparent area; $0.1 \mathrm{~V} / \mathrm{s} 12 \mathrm{M} \mathrm{H}_{2} \mathrm{SO}_{4} ; 25^{\circ} \mathrm{C}$. (O) Plot of $Q_{\mathrm{a}}$ vs. $\ln \tau$. Data corresponding to $E_{\tau}=1.15 \mathrm{~V}$ and $E_{\tau}=1.58 \mathrm{~V}$.

The $E / I$ electroreduction profiles run after holding the potential at $E_{\mathrm{s}, \mathrm{a}}=E_{\tau}$ during the time $\tau$, show a progressive increase of charge with $\tau$. When $E_{\tau}=0.75 \mathrm{~V}$ (Fig. 4) the electroreduction response is similar to that observed in the stabilized $E / I$ profile. This suggests that, in principle, there is only an accumulation of products at $E_{\tau}$ during the time $\tau$, since no distinction can be made either between different structures or stability change of the oxygen-containing species through the shift of the corresponding electroreduction potential $\left(\Delta E_{\mathrm{p}, \mathrm{r}}=E_{\mathrm{p}, \mathrm{r}}^{\mathrm{a}}-E_{\mathrm{p}, \mathrm{r}}\right)$, where $E_{\mathrm{p}, \mathrm{r}}^{\mathrm{a}}$ is the potential of the electroreduction current peak of the aged species [21]. The latter effect is, however, observed when $E_{\tau}=1.15 \mathrm{~V}, 1.45 \mathrm{~V}$ and $1.58 \mathrm{~V}$ (Fig. 5). In these cases, the electroreduction peak shifts towards more negative potentials, linearly with $\ln \tau$. This can be interpreted as the formation of an O-containing species which is more stable than that corresponding to the conventional $E / I$ profile run under a RTPC. The magnitude of $\Delta E_{\mathrm{p}, \mathrm{r}}$ depends on $E_{\mathrm{s}, \mathrm{a}}$. The increase of both $Q_{\mathrm{a}}$ and $\Delta E_{\mathrm{p}, \mathrm{r}}$ with $\tau$, when $E_{\tau}>0.75 \mathrm{~V}$, indicates an increasing irreversibility of the overall electroreduction process (Fig. 5). When $E_{\tau}=1.58 \mathrm{~V}$, the $\Delta E_{\mathrm{p}, \mathrm{r}}$ vs. $\ln \tau$ and the $Q_{\mathrm{c}}$ vs. $\ln \tau$ relationships also show a good correspondence.

\section{Potentiodynamic ageing}

The $E / I$ profile that results after applying the potentiodynamic ageing perturbation program [22] depends on the frequency, number of cycles and switching potentials of the intermediate repetitive triangular potential sweep (IRTPS) as it occurred with the Pt group metals. When the IRTPS is applied at $1 \mathrm{~V} / \mathrm{s}$ for $1 \mathrm{~min}$ with the amplitude $(A)$ between $E_{\mathrm{s}, \mathrm{a}}=1.58 \mathrm{~V}$ and $E_{\mathrm{s}, \mathrm{c}}^{\prime}$ is fixed in the $0.3 \mathrm{~V}<\mathrm{A}<$ $1.3 \mathrm{~V}$, the electroreduction profile recorded afterwards, shows a net shift of the peak potential towards lower values. This shift can be attributed to the ageing of the $\mathrm{O}$-containing species. However, in the case of $\mathrm{Ru}$ in comparison with $\mathrm{Pt}$, no 


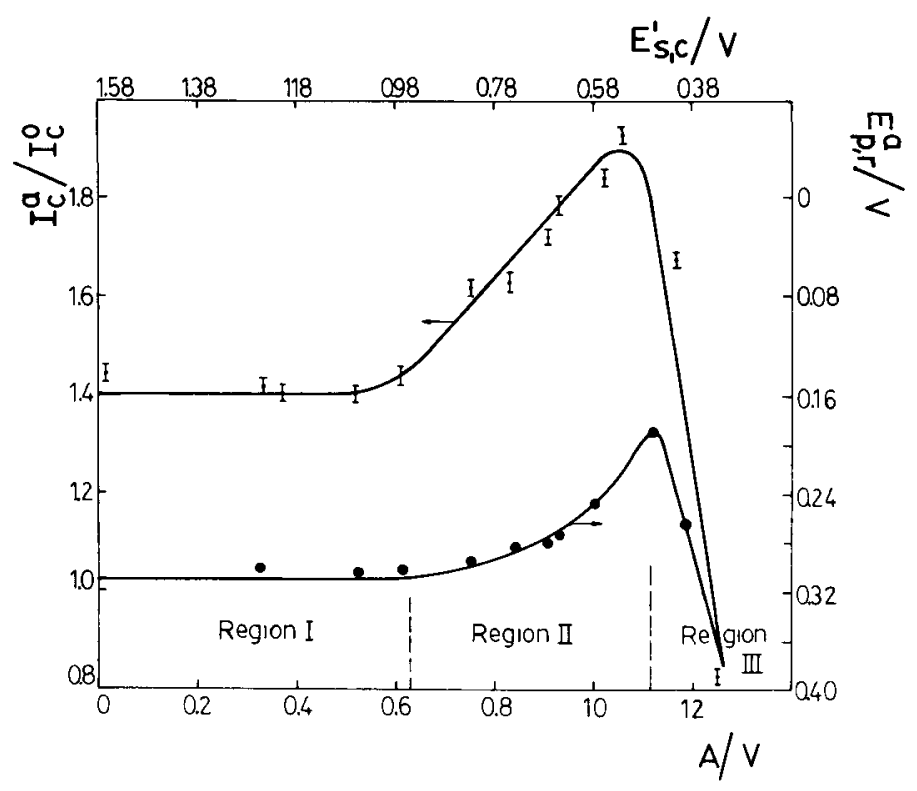

Fig. 6. $I_{\mathrm{c}}^{\mathrm{a}} / I_{\mathrm{c}}^{0}$ vs. $A$ and $\Delta E_{\mathrm{p} . \mathrm{r}}$ vs. $A$ plots for a $E_{\mathrm{s} . \mathrm{a}}=1.58 \mathrm{~V}$. Ruthentzed $P t, 0.25 \mathrm{~cm}^{2}$ apparent area; 0.1 $\mathrm{V} / \mathrm{s} ; 12 \mathrm{M} \mathrm{H}_{2} \mathrm{SO}_{4} ; 25^{\circ} \mathrm{C}$.

perturbation conditions for the splitting of the electroreduction profile could be achieved. This fact seems to indicate that there is no $E_{\mathrm{s}, \mathrm{c}}^{\prime}$ value where the $\mathrm{Ru}$ surface is actually able to provide a partially oxygen-free surface. On the other hand, as $A$ increases, the average potential of the IRTPS becomes lower, a fact which should correspond to a decrease in the accumulation of charge during the IRTPS. However, the plot of the $I_{\mathrm{c}}^{\mathrm{a}} / I_{\mathrm{c}}^{0}$ ratio against $A$ (Fig. 6) $\left(E_{\mathrm{s} . \mathrm{a}}=1.58 \mathrm{~V}\right)$ involves three regions; $I_{\mathrm{c}}^{\mathrm{a}}$ and $I_{\mathrm{c}}^{0}$ are, respectively, the current peak with and without accumulation of charge. The $I_{\mathrm{c}}^{\mathrm{a}} / I_{\mathrm{c}}^{0}$ ratio obtained after holding for $1 \mathrm{~min}$ at $E_{\mathrm{s}, \mathrm{a}}$ is taken for comparison, since it corresponds to $A=0$. The first region covers from $A=0.0 \mathrm{~V}$ to $A=0.6 \mathrm{~V}$. In this range the $I_{\mathrm{c}}^{\mathrm{a}} / I_{\mathrm{c}}^{0}$ ratio is independent of $A$ and it coincides with that resulting after applying the potentiostatic ageing program at $1.58 \mathrm{~V}$. This means that during the IRTPS no apparent changes of the oxidized Ru electrode occur.

In the second region, which extends between $0.6 \mathrm{~V}$ and $1.1 \mathrm{~V}$, the charge increases with $A$ and it becomes greater than that found after holding the potential at $E_{\tau}$. The IRTPS in the second region favours the production of other O-containing species which are apparently absent at higher potentials. Besides, the accumulation of charge depends on the frequency of the IRTPS and on the amount of oxygen-containing film forming species on the electrode.

Region III covers from $1.1 \mathrm{~V}$ to $1.3 \mathrm{~V}$. In this region, the accumulation of charge decreases with $A$, and for $A$ greater than $1.2 \mathrm{~V}$, it attains values even smaller than those recorded under a conventional RTPS. This corresponds to the shift of the 
average potential of the IRTPS with $A$, as already pointed out.

It should be noticed that there is a reasonable correspondence between the $E_{\mathrm{p}, \mathrm{r}}^{\mathrm{a}} \mathrm{vs}$. $A$ and the $\mathrm{I}_{\mathrm{c}}^{\mathrm{a}} / I_{\mathrm{c}}^{0}$ vs. $A$ plots, which indicates that the location of the electroreduction current peak is mainly determined by the magnitude of the charge accumulated at the electrode/solution interface during the IRTPS. Consequently, both the structure and the electrochemical response of the oxygen-containing layer depend on the layer thickness. The thickest layer is obtained when $A=1.05\left(E_{\mathrm{s}, \mathrm{a}}=1.58 \mathrm{~V}\right)$, namely, when $E_{s, c}^{\prime}$ involves the removal and rebuilding of $15-25 \%$ oxide charge. It is likely that the main component of the thick layer in this case is a hydrated $\mathrm{RuO}_{2}$.

The above description is also fulfilled when $E_{\mathrm{s}, \mathrm{a}}=1.25 \mathrm{~V}$, but then the accumulation of charge is lower than when $E_{\mathrm{s}, \mathrm{a}}=1.58 \mathrm{~V}$ and the greatest irreversibility of the electroreduction process is observed for $A$ values greater than those corresponding to

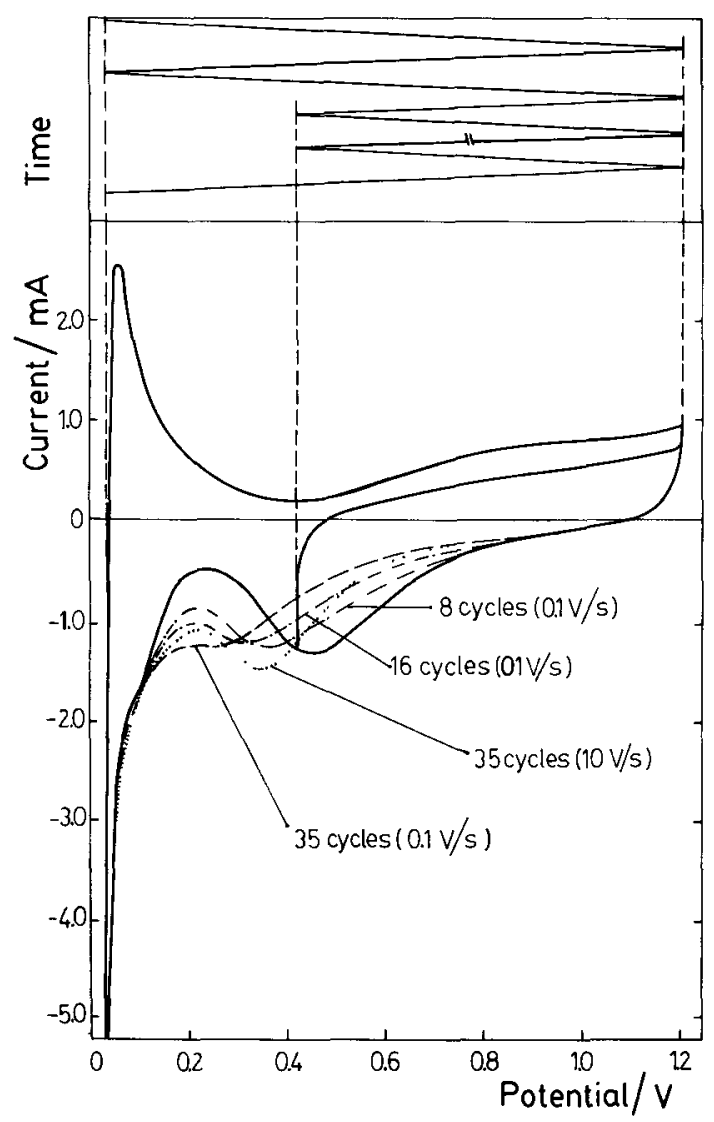

Fig. 7. Potentiodynamic $I / E$ profiles obtained after the potentiodynamic ageing at $0.1 \mathrm{~V} / \mathrm{s}$ between $E_{\text {s.a }}=1.20 \mathrm{~V}$ and $E_{\mathrm{s}, \mathrm{c}}^{\prime}=0.48 \mathrm{~V}$ for 8, 16 and 35 IRTPC. The dotted profile corresponds to 35 IRTPC at $10 \mathrm{~V} / \mathrm{s}$. In both cases reference $I / E$ profile before the IRTPC was recorded at $0.1 \mathrm{~V} / \mathrm{s}(-$ Ruthenized, $\mathrm{Pt}, 0.25 \mathrm{~cm}^{2}$ area; $12 \mathrm{M} \mathrm{H}_{2} \mathrm{SO}_{4} ; 25^{\circ} \mathrm{C}$. 
the largest accumulation of charge. After applying the potentiodynamic ageing perturbation program the conventional $E / I$ profile can be recovered only after a few RTPS. The recovery time depends on the perturbation parameters of both the IRTPS and the subsequent RTPS. To avoid any error due to a possible residual sintering of the electrode in the comparison of charges obtained under different ageing conditions, the reference charge is taken as that of the conventional RTPS justly preceding the corresponding ageing program.

Under a constant $E_{\mathrm{s}, \mathrm{a}}$ and comparable conditions, tha magnitude of $A$ plays a double influence on the electroreduction profile run subsequently to the IRTPS, namely the total electroreduction charge, $Q_{\mathrm{c}}$, and on the position and shape of the corresponding current peak.

The influence of the potential sweep during the IRTPS gives additional information about the complexity of the electrochemical process. For this purpose $E_{\mathrm{s}, \mathrm{a}}$ is fixed at $1.25 \mathrm{~V}$ and $E_{s . c}^{\prime}$ is adjusted to remove and rebuild during the IRTPS $60 \%$ of the oxygen-containing layer originally electroformed. Two different runs were made. The potential sweep at the IRTPS was chosen as $0.1 \mathrm{~V} / \mathrm{s}$ and $10 \mathrm{~V} / \mathrm{s}$, respectively. At $0.1 \mathrm{~V} / \mathrm{s}$ the IRTPS was applied for 8,16 and 35 cycles, and at $10 \mathrm{~V} / \mathrm{s}$ for 35 cycles. The corresponding electroreduction profiles after the IRTPS (Fig. 7) for the same number of IRTPS show a remarkable difference, namely, at $0.1 \mathrm{~V} / \mathrm{s}$, a wide electroreduction peak is recorded, while at $10 \mathrm{~V} / \mathrm{s}$ it becomes steeper. This result reveals that the oxide layer is formed by different species whose distribution depends strongly on $v$. At low $v$, there is an apparently wide distribution of O-containing species, which, depite the low $v$ value, have their re-accomodation process remarkably inhibited, probably by the interference, in this case, of the anion adsorption.

\section{Triangular modulated voltammetry (TMV)}

The TM potentiodynamic profile run in the positive potential direction (Fig. 8) shows a complex response throughout the potential range where the O-containing species, either electro-adsorbed or oxide forming, is formed. The complex response involves at least one reversible and one irreversible component. The current peaks related to the contours of the reversible component are located at $0.56 \mathrm{~V}$, a potential falling within the potential range where species such as $\mathrm{Ru}^{2+}$, and surface $\mathrm{Ru}(\mathrm{OH})$ can be formed. On the other hand, the contribution of the irreversible component is more remarkable, as the base potential sweep extends to a potential more positive than $0.56 \mathrm{~V}$. Similarly, the profile resulting when the base potential sweep moves towards the negative potential region, also involves the contribution of a reversible process, which is characterized by the current peaks appearing at $0.80 \mathrm{~V}$, and an irreversible process. The latter is observed in the potential range just preceding the electroformation of $\mathrm{H}$-adatoms. These experiments clearly demonstrate the participation of two distinct reversible redox couples in the overall process, related to the electroformation of different oxygen-containing species on $\mathrm{Ru}$ in the acid electrolyte. In both cases, each reversible process is followed by a net irreversible electrochemical reaction. 


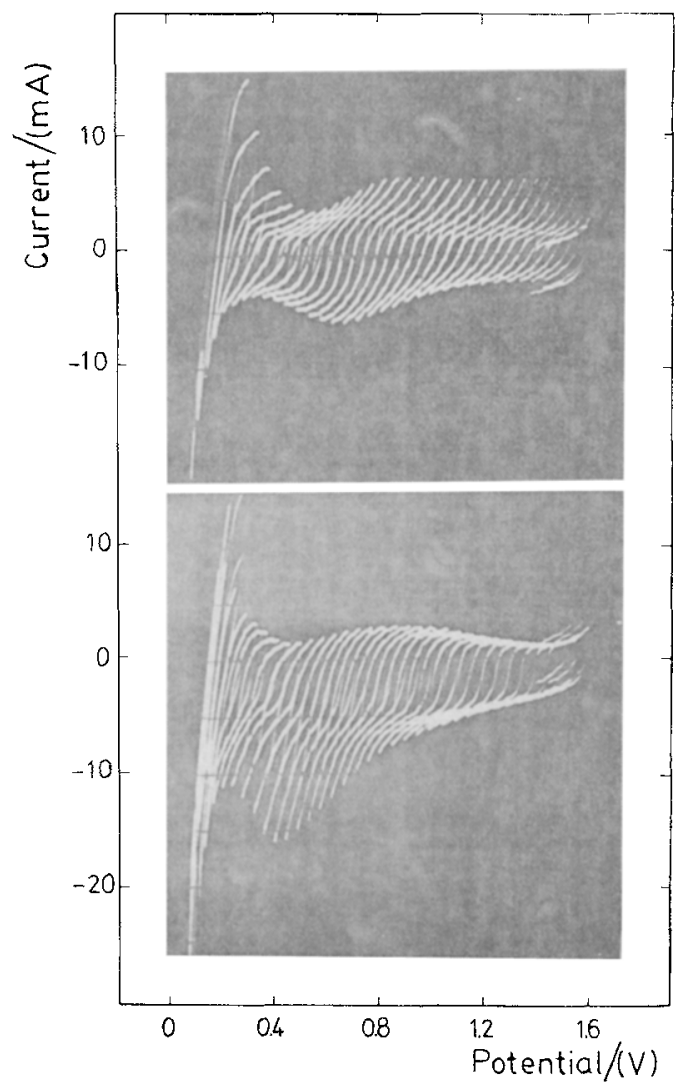

Fig. 8. Triangularly modulated potentiodynamic $I / E$ displays. Guide sweep rate $0.5 \mathrm{~V} / \mathrm{s}$; modulating potential sweep rate $5 \mathrm{~V} / \mathrm{s}$; modulation amplitude $0.2 \mathrm{~V}$. The upper picture corresponds to the positive going potential scan and the lower picture to the reverse potential scan. Ruthenized Pt, $0.25 \mathrm{~cm}^{2}$ area; $12 \mathrm{M} \mathrm{H}_{2} \mathrm{SO}_{4} ; 25^{\circ} \mathrm{C}$.

\section{DISCUSSION}

The potentiodynamic response of $\mathrm{Ru}$ in acid electrolytes reveals that the overall reaction involves several successive stages and it exhibits potential regions where the electroformation and the electroreduction of the anodic oxygen-containing layer behave either as reversible or as irreversible reactions, depending on the electrode history and perturbation conditions $[13,20]$. The anodic reaction is initiated when the potential applied to the electrode exceeds $0.4 \mathrm{~V}$ (Fig. 1). This potential is close to the equilibrium potential of the reaction:

$\mathrm{Ru}=\mathrm{Ru}^{2+}+2 e^{-}$

$E^{0} /(\mathrm{V})=0.455$. In this respect, the equilibrium electrodissolution potential of Ru is, 
comparatively, much lower than that of other metals of the Pt group [23]. Hence, it is reasonable that in the case of ruthenium, reaction (1) appears as a relatively fast initial step at low applied potentials, coupled to the corresponding hydrolysis equilibria:

$\mathrm{Ru}^{2+}+\mathrm{H}_{2} \mathrm{O}=\mathrm{RuOH}^{+}+\mathrm{H}^{+}$

$2 \mathrm{RuOH}^{+}=\mathrm{Ru}^{2+}+\mathrm{Ru}(\mathrm{OH})_{2}$

Nevertheless, the metal electrodissolution and surface oxide formation can also be interpreted thoughout a series of steps, as are those already postulated for the electrodissolution and passive layer formation on the transition metals. Thus, the following reactions should be taken into account:

$$
\begin{aligned}
& \mathrm{Ru}+\mathrm{H}_{2} \mathrm{O}=\mathrm{Ru}(\mathrm{OH})+\mathrm{H}^{+}+e^{-} \\
& \mathrm{Ru}(\mathrm{OH})=\mathrm{Ru}(\mathrm{OH})^{+}+e^{-} \\
& 2 \mathrm{Ru}(\mathrm{OH})^{+}=\mathrm{Ru}(\mathrm{OH})_{2}+\mathrm{Ru}^{2+} \\
& \mathrm{Ru}(\mathrm{OH})_{2}=\mathrm{RuO} \cdot \mathrm{H}_{2} \mathrm{O}
\end{aligned}
$$

Both reaction sequences explain the initial stages of the O-electro-adsorption and oxide formation on ruthenium, as well as the relatively great dissolution rate of the metal during cycling [10]. Taking into account these reactions and the charge involved in the $0.4 \mathrm{~V}$ to $0.6 \mathrm{~V}$ range (Fig. 1), one concludes that the first stage of the electrooxidation process yields the equivalent of a monolayer which is probably a mixture of oxygen-containing species such as $\mathrm{Ru}_{2} \mathrm{O}, \mathrm{Ru}(\mathrm{OH})$ or $\mathrm{RuO} \cdot \mathrm{H}_{2} \mathrm{O}$. The corresponding electrochemical reactions behave as reversible surface voltammetric processes (Fig. 8). In this case the composition of the surface layer should depend strongly on the dehydrating characteristics and composition of the electrolyte. Otherwise, the specific adsorption of the $\mathrm{HSO}_{4}^{-}$ion on the ruthenized electrode inhibits the initiation of the surface oxidation process as it occurs, for instance, in the case of $\mathrm{Pt}$ in aqueous $\mathrm{H}_{2} \mathrm{SO}_{4}$ electrolytes [24,25]. In principle, the effect produced by the increase of $\mathrm{H}_{2} \mathrm{SO}_{4}$ concentration in the potentiodynamic response of the surface oxide process is similar to that of a decreasing temperature.

Once the initial layer has been electroformed, the following stage can be interpreted as the electrooxidation of $\mathrm{Ru}(\mathrm{II})$ into $\mathrm{Ru}(\mathrm{III})$ species at the electrode surface, since the $E^{0}$ value related to the electroformation of $\mathrm{Ru}_{2} \mathrm{O}_{3}$ from $\mathrm{Ru}$, according to the reaction:

$2 \mathrm{Ru}+3 \mathrm{H}_{2} \mathrm{O}=\mathrm{Ru}_{2} \mathrm{O}_{3}+6 \mathrm{H}^{+}+6 e^{-}$

is $E^{0} /(\mathrm{V})=0.738$. The formation of $\mathrm{Ru}_{2} \mathrm{O}_{3}$ can be associated mainly with the following overall reactions:

$$
\begin{aligned}
& \mathrm{Ru}(\mathrm{OH})_{2}+\mathrm{H}_{2} \mathrm{O}=\mathrm{Ru}(\mathrm{OH})_{3}+\mathrm{H}^{+}+e^{-} \\
& 2 \mathrm{Ru}(\mathrm{OH})_{3}=\mathrm{Ru}_{2} \mathrm{O}_{3} \cdot 3 \mathrm{H}_{2} \mathrm{O}
\end{aligned}
$$

According to these reactions the number of electrons per $\mathrm{Ru}$ atom should be in 
the range 1.5 to 3 times that involved throughout the first stage. This agrees with the results shown in Fig. 1. The fact that the actual figure derived from Fig. 1 lies between the above-mentioned limiting values, can be explained in terms of the formation of non-stoichiometry ruthenium-oxygen surface species on the electrode, as previously pointed out by various authors [10]. Then, as a consequence of reactions (1-3), the probable limiting sandwich-type structure of the interface at this stage can be represented as $\mathrm{Ru} / \mathrm{RuO} \cdot \mathrm{H}_{2} \mathrm{O} / \mathrm{Ru}_{2} \mathrm{O}_{3} \cdot 3 \mathrm{H}_{2} \mathrm{O}$. This implies that the growth in thickness of the oxide layer fits a $Q_{\mathrm{a}}$ vs. $\ln \tau$ linear relationship. This law has been already reported for different film growth processes [26], including oxide formation on ruthenium in acid electrolytes [6,27]. However, the fact that the increase in $Q_{\mathrm{a}}$ is accompanied by a progressive shift of $E_{\mathrm{p}, \Gamma}$, supports the idea that the average composition of the film is thickness-dependent, a fact which can be explained in terms of a complex sandwich-type structure of the interface involving at least three different regions: the metal/inner oxide film, the inner film/outer film and the outer film/electrolyte regions. The black appearance of the electrode surface, resulting at $0.8 \mathrm{~V}$, is reported the same for such compounds as $\operatorname{Ru}(\mathrm{OH})_{3}$ or $\mathrm{Ru}_{2} \mathrm{O}_{3} \cdot 3 \mathrm{H}_{2} \mathrm{O}$.

Likewise, within the potential range where an intermediate oxidation state such as $\mathrm{Ru}(\mathrm{II})$ is formed, disproportionation reactions become possible [28]. This can be represented by the following reaction:

$3 \mathrm{Ru}(\mathrm{II})=2 \mathrm{Ru}(\mathrm{III})+\mathrm{Ru}(0)$

This type of reaction, already postulated for $\mathrm{Rh}$ electrodes in acid electrolytes [29], may explain the difference between the anodic and the cathodic charge balance which results from potentiodynamic sweeps at different potential sweep rates.

The region between $0.8 \mathrm{~V}$ and $1.2 \mathrm{~V}$ corresponds to the one where $\mathrm{RuO}_{2}$ is stable. $\mathrm{RuO}_{2}$ - based film anodes prepared by thermal decomposition of $\mathrm{RuCl}_{3} \cdot n \mathrm{H}_{2} \mathrm{O}$ on inert substrate are especially employed in chlor-alkali cells [30,31]. The following equilibria are related to the formation of $\mathrm{RuO}_{2}$ :

$$
\begin{array}{ll}
\mathrm{Ru}^{2+}+2 \mathrm{H}_{2} \mathrm{O}=\mathrm{RuO}_{2}+4 \mathrm{H}^{+}+2 e^{-} & E^{0}=1.120 \mathrm{~V} \\
\mathrm{Ru}_{2} \mathrm{O}_{3}+\mathrm{H}_{2} \mathrm{O}=2 \mathrm{RuO}_{2}+2 \mathrm{H}^{+}+2 e^{-} & E^{0}=0.937 \mathrm{~V}
\end{array}
$$

These reactions suggest that in the $0.8 \mathrm{~V}$ to $1.2 \mathrm{~V}$ range the $\mathrm{RuO}_{2}$ layer may be formed in two different ways, namely from the electrodissolution of $\mathrm{Ru}$ throughout the $\mathrm{Ru}^{2+}$ species and from the electrooxidation of the $\mathrm{Ru}_{2} \mathrm{O}_{3}$ layer. The structure of $\mathrm{RuO}_{2}$ at the interface probably corresponds to a hydrated form such as $\mathrm{RuO}_{2} \cdot 2$ $\mathrm{H}_{2} \mathrm{O}$ or $\mathrm{Ru}(\mathrm{OH})_{4}$. Finally, in acid solutions at potentials greater than $1.3 \mathrm{~V}$, the following reaction is feasible:

$\mathrm{RuO}_{2}+2 \mathrm{H}_{2} \mathrm{O}=\mathrm{RuO}_{4}+4 \mathrm{H}^{+}+4 e^{-}$

$E^{0}=1.387 \mathrm{~V}$. The possible $\mathrm{RuO}_{4}$ species corresponds to a peroxidic structure, as are those already described for metals such as $\mathrm{Au}, \mathrm{Rh}$ and $\mathrm{Pd}$ [32-34]. In the acid electrolytes $\mathrm{RuO}_{4}$ decomposes according to the following chemical reaction [35]:

$\mathrm{RuO}_{4}+\mathrm{H}_{2} \mathrm{O}=\mathrm{RuO}_{2} \cdot \mathrm{H}_{2} \mathrm{O}+\mathrm{O}_{2}$ 
The preceding discussion on the formation of different oxide species with a varying degree of hydration is based mainly on the coincidence between the thermodynamic predictions for the reactions involving bulk species and the fast kinetic response of the electrochemical system found, at least, in two wide potential ranges in TMV, namely between $0.45 \mathrm{~V}$ and $0.65 \mathrm{~V}$ along the positive-going sweep, and between $0.70 \mathrm{~V}$ and $0.90 \mathrm{~V}$ along the negative-going potential sweep. The rapid kinetic response of the system can be attributed to processes involving fast electron and proton transfers, with the simultaneous changes in the valence state of the metal atoms, that occur simultaneously through a series of reversible steps, as has been observed for other oxo-hydroxide metal electrodes such as iridium in acid solution [36-38]. In this respect the general mechanism of the reversible steps are explained through the reaction suggested earlier by Michell, Rand and Woods [10].

$\mathrm{RuO}_{x}\left(\mathrm{H}_{2} \mathrm{O}\right)_{y}=\mathrm{RuO}_{(x+\delta)}\left(\mathrm{H}_{2} \mathrm{O}\right)_{(y-\delta)}+2 \delta \mathrm{H}^{+}+2 \delta e^{-}$

This means the establishment of an oxide film in which rapid redox processes take place [6]. At the oxide-covered electrode the rate of charge transfer is determined by redox processes that occur mainly at the internal portion of the film [26], according to the general reaction pathway recently proposed by Gottesfeld and Srinivasan [39].

On the other hand, as the initial stage of the reaction is assigned to the ionization of the metal, it is reasonable that aging effects under constant charge conditions are absent, and instead there is a shift of the electroreduction process towards a lower potential as the average film thickness increases. Therefore, it is quite likely that the average composition of the anodically formed layer depends on the time required to form it, and, in general, on the history of the anodic film. This is related to the fact that the maximal charge associated with the anodic film is achieved when the IRTPS under the potentiodynamic aging perturbation program involves a $E_{\mathrm{s}, \mathrm{c}}^{\prime}$ value in the potential ranges of regions II and III (Fig. 1). i.e. when processes (3) and (5) participate in the removal and rebuilding of the anodic film. Conversely, when the IRTPS amplitude involves an $E_{s, c}^{\prime}$ value in the potential range of either region I or IV, no oxide accumulation is achieved, because of reactions (1), (6) and (7).

Additional information about the kinetics and mechanism of these processes comes from the influence of the $\mathrm{H}_{2} \mathrm{SO}_{4}$ concentration on the charge distribution in the $E / I$ displays. From these results the influence of $\mathrm{HSO}_{4}^{-}$ion becomes evident in two aspects: firstly, by producing a partial blockage of the electrode which inhibits the initiation of the electrooxidation process, and secondly, by making the shape of the corresponding electroreduction profile more extended along the potential axis. This flattening indicates that the successive oxidation stages of the initial oxide film are to some extent impeded, probably because the greater the $\mathrm{H}_{2} \mathrm{SO}_{4}$ concentration, the lower the activity of water at the interface. Consequently, the relative concentration of oxide species which can be reversibly electroreduced is increased and there is a larger electroreduction current contribution at potentials that are closer to $E_{\mathrm{s}, \mathrm{a}}$. The inhibiting influence of $\mathrm{HSO}_{4}^{-}$is also shown by the greater overpotential required to form the initial $(\mathrm{OH})$ layer on $\mathrm{Ru}$, similarly to results already reported for other metals $[24,40]$. 


\section{ACKNOWLEDGEMENTS}

INIFTA is sponsored by Consejo Nacional de Investigaciones Científicas y Técnicas, the Universidad Nacional de La Plata and the Comision de Investigaciones Científicas (Provincia de Buenos Aires).

\section{REFERENCES}

1 M. Vuković, H. Angerstein-Kozlowska and B.E. Conway, J. Appl. Electrochem., 12 (1982) 193.

2 L.D. Burke and J.F. O'Neill, J. Electroanal. Chem., 101 (1979) 341.

3 G. Lodi, E. Sivieri, A. De Battisti and S. Trasatti, J. Appl. Electrochem., 8 (1978) 135.

4 L.D. Burke and O.J. Murphy, J. Electroanal. Chem., 101 (1979) 351.

5 F. Hine, M. Yasuda, T. Noda, T. Yoshida and J. Obuda, J. Electrochem. Soc., 126 (1979) 1439.

6 S. Hadzi-Jordanov, H. Angerstein-Kozlowska, M. Vuković and B.E. Conway, J. Electrochem. Soc., 125 (1978) 1471.

7 S. Hadzi-Jordanov, H. Angerstein-Kozlowska, M. Vuković and B.E. Conway in J.D. Mc Intyre, S. Srinuvasan and F.G. Will (Eds.) Electrochemical Society Symposium on Electrode Materials and Processes for Energy Conversion and Storage, The Electrochemical Society, Princeton, Vol. 77-6, 1977, p. 185.

8 G. Bélanger and A.K. Vijh in A.K. Vijh (Ed.), Oxides and Oxıde Films, Marcel Dekker, New York, 1977 , p. 1.

9 L.D. Burke and J.K. Mulcahy, J. Electroanal. Chem., 73 (1976) 207.

10 D. Michell, D.A.J. Rand and R. Woods, J. Electronal. Chem., 89 (1978) 11.

11 R. Woods in A.J. Bard (Eds.), Electroanalytical Chemistry, Vol. 9, Marcel Dekker, New York, 1976, p. 1.

12 S. Hadzi-Jordanov, H. Angerstein-Kozlowska, M. Vuković and B.E. Conway, J. Phys. Chem., 81 (1977) 2271.

13 B.E. Conway and J. Mozota, The Electrochemical Soc., Inc. Spring Meeting, Minneapolis, MN, May $10-15,1981$, p. 992.

14 S. Gottesfeld and J.D.E. McIntyre, J. Electrochem. Soc., 126 (1979) 742.

15 D. Galizzioli, F. Tantardini and S. Trasatti, J. Appl. Electrochem., 4 (1974) 57; ibid 5 (1975) 203.

16 T. Kessler, A.M. Castro Luna, W.E. Triaca and A.J. Arvía, in preparation.

17 P. Stonehart and P.A. Zucks, Electrochim. Acta, 17 (1972) 2333.

18 A. Bolzán, M.E. Martins and A.J. Arvía, J. Electroanal. Chem., in press.

19 C. Pallotta, N.R. de Tacconi and A.J. Arvía, J. Electroanal. Chem., in press.

20 L.D. Burke, J.K. Mulcahy and S. Venkatesan, J. Electroanal. Chem., 81 (1977) 339.

21 N.R. de Tacconi, A.J. Calandra and A.J. Arvía, J. Electroanal. Chem., 51 (1974) 25.

22 M.E. Folquer, N.R. de Tacconi and A.J. Arvía, J. Electrochem. Soc., 126 (1979) 592.

23 M. Pourbaix, Atlas of Electrochemical Equilibrium in Aqueous Solutions, Pergamon Press, New York, 1966.

24 I.I. Labkovskaya, V.I. Luk'yanycheva and V.S. Bagotskii, Elektrokhimiya, 5 (1969) 580.

25 R.O. Lezna, N.R. de Tacconi and A.J. Arvía, J. Electrochem. Soc., 126 (1979) 2140.

26 M.J. Dignan, in J.O'M. Bockris, B.E. Conway, E. Yeager and R.E. White (Eds.), Comprehensive Treatise of Electrochemistry, Vol. 4, Plenum Press, New York, 1981, p. 247.

27 F. Colom and M.J. Gonzalez-Tejena, ISE, 31st Meeting-Extended Abstract A28, Venice, Italy, 1980, p. 217.

28 J.F. Llopis and I.M. Tordesillas in A.J. Bard (Ed.), Encyclopedia of Electrochemistry of the Elements, Vol. 6, Marcel Dekker, New York, 1976, p. 277.

29 C.D. Pallotta, N.R. de Tacconi and A.J. Arvía, Electrochim. Acta, 26 (1980) 261.

30 H.V.K. Udupa, R. Thangappan, B.R. Yadar and P. Subbiath, Chem. Age India, 23 (1975) 545.

31 R.R. Dukes and R.G. Milner, J. Electrochem. Soc., 117 (1970) 9C. 
32 S. Shibata, Bull. Chem. Soc. Jpn., 38 (1965) 1330.

33 A. Hickling and G. Vrojsek, Trans. Faraday Soc., 57 (1951) 123.

34 M.I. Florit, M.E. Martins and A.J. Arvía, J. Electroanal. Chem., 126 (1981) 255.

35 J.M. Fletcher, W.E. Gardner, B.F. Greenfield, M.J. Holloway and M.H. Rand, J. Chem. Soc. (A), (1968) 653.

36 D.A.J. Rand and R. Woods, J. Electroanal. Chem., 55 (1974) 375.

37 J.O. Zerbıno, N.R. de Tacconi and A.J. Arvía, J. Electrochem. Soc., 125 (1978) 1266.

38 J.O. Zerbino and A.J. Arvía, J. Electrochem. Soc., 126 (1979) 93.

39 S. Gottesfeld and S. Srinivasan, ref 13, p. 1256.

40 M.S. Chemeris, A.G. Stromberg and Yu.B. Vasiliev, Elektrokhimiya, 11 (1975) 560. 